\title{
Novel Applications for Fog Water Harvesting
}

\author{
Gloria Morichi ${ }^{1}$, Lucas Bandeira Calixto ${ }^{2}$, Alessandra Zanelli ${ }^{1}$ \\ ${ }^{1}$ Polytechnic University of Milan, Milan, Italy \\ ${ }^{2}$ Polytechnic University of Turin, Turin, Italy \\ Email: alessandra.zanelli@polimi.it
}

How to cite this paper: Morichi, G., Calixto, L.B. and Zanelli, A. (2018) Novel Applications for Fog Water Harvesting. Journal of Geoscience and Environment Protection, 6, 26-36. https://doi.org/10.4236/gep.2018.63004

Received: January 31, 2018

Accepted: March 10, 2018

Published: March 13, 2018

\begin{abstract}
In a scenario of climate changes and increasing stress upon available fresh water resources like rivers, lakes and aquifers, collecting fog water is a promising yet relatively unexplored potentiality. Providing sufficient water and reducing water extraction's environmental impact at the same time can be a challenge with conventional ways, but fog harvesting technology presents itself as a powerful and efficient alternative. Water availability profoundly determined regional economic benefit, social relations and it also influenced environmental security and ecosystem services. Underdeveloped countries have been dealing with water scarcity issue for decades, but also wealthy countries will have to face the water crisis soon, due to unsustainable development processes. A review of the state of the art highlights the most relevant parameters to deal with when discussing about fog water harvesting. In regions with frequent fog events, this technology already proved to be a sustainable drinking water resource for rural communities and their low per capita water usage was provided by basic devices utilization. Nevertheless, in this paper, different fog water harvesting applications are investigated, besides the already existing fresh-water collection, reforestation and agricultural use. Further options, such as building components, outdoor activities and domestic devices are considered, according to different parameters, such as economic benefits, possibility of standardized production, life cycle and market attractiveness. A desirable novel concept would become relevant in specific contexts, thanks to multiple functions, offering locals designed and customized solutions. Also noteworthy are the landscape impact of such devices and the effects of the project in terms of places regeneration, raising awareness and "green" conscience creation. The study of local climatic data and improvement in fog collector applications, integration with architectural and landscape design, will expand the regions where fog harvesting can be applied and its sustainable improvements.
\end{abstract}




\section{Keywords}

Fog Water Harvesting, Urban Regeneration, Water Scarcity, Sustainable Water Resource

\section{Introduction}

Among the many factors-for instance food and energy security policies, macro-economic processes such as trade globalization, changing diets and increasing consumption-that largely influence water demand, the greater applied stress to water resources is related to population growth and urbanization. It is estimated that by 2050, global water demand will face a $55 \%$ increment, mainly related to higher demands from manufacturing, thermal electricity generation and domestic use [1]. In order to preserve global water supplies and relieve the stress on conventional, over-exploited fresh water sources, fog water harvesting stands as a promising solution. Fog collection is a passive, low cost and sustainable technology that already provided with fresh water many rural villages in remote and semi-arid region [2].

Fog potentialities have already been studied in more than 20 countries, in particular along the coast of northern South America [3] [4]; the Canary Islands [5], Morocco [6], South Africa [7] [8], Oman [9]; Arabia [10], western Mediterranean basin [11], Namibia [12].

The objectives of this paper are to provide an overview of regional water stress levels and of fog formation processes and suitable climatic regions; to review current models and designs for fog water harvesting, with reference to some study cases. The result would include some suggestions regarding new scenarios for fog harvesting application, e.g. urban integration, identifying chances of improvement and possibility of generating a positive impact on urban water resource management.

\section{Water Scarcity}

Freshwater supplies are erratically distributed in time and space. From one year to the next, there can be considerable variability between arid and humid climates and wet and dry seasons. It is water, not land, which is the limiting factor in most agricultural practices around the world, especially in arid environments. The World Water Development Report [13] defined water scarcity as:

"The point at which the aggregate impact of all users impinges on the supply or quality of water under prevailing institutional arrangements to the extent that the demand by all sectors, including the environment, cannot be satisfied fully [...], a relative concept [ that] can occur at any level of supply or demand."

There are major uncertainties about the amount of water required to meet demand for food, energy and other human uses, and to sustain ecosystems. These uncertainties are compounded by the impact of climate change that affects 
both water resources and its demands for all uses directly. Mitigation measures are focused on reducing energy consumption and carbon emissions, while smaller efforts are addressed to adaptation planning to manage increasing hydrological variability and extreme weather events. Trends in ecosystems, including the life they support, are telling us that things are out of balance. Ecosystems do not consume water-they supply and recycle it; and if they met reduced water levels than necessary, their beneficial output is also reduced. Improving water resource management, increasing access to safe drinking water and basic sanitation and promoting hygiene have the potential to improve the quality of life of billions of individuals. They are also critical for the achievement of the goals to reduce child mortality, improve maternal health, reduce waterborne diseases and class and gender inequality (Figure 1) [14].

Cost is another factor that impacts water resource issues. Water distribution infrastructure is expensive to build, and while water may exist in one area, pumping and hauling it to another one increase costs so much that it may be unaffordable to many of the communities who need it the most. Energy and water are intricately connected. Although different sources of energy and electricity exist, all require water for various production processes, including extraction of raw materials, cooling in thermal processes, cleaning materials, cultivation of crops for biofuels, and powering turbines. Conversely, energy is required to make water resources available for human use and consumption through pumping, transportation, treatment, desalination and irrigation. This double-sided interdependency of both resources has been coined "the water-energy nexus", and introduces key cross-sectoral vulnerabilities.

As a general trend, energy and electricity consumption are likely to increase over the next 25 years in all world regions, with direct implications for the water resources needed to supply this energy [15].

\section{Water Scarcity Related Socioeconomic Issue}

Not surprisingly, water insufficiency often correlates to worse living conditions. Water scarcity is becoming increasingly a worldwide preoccupation giving the fast growth rates of populations in already water-stressed regions, and even in

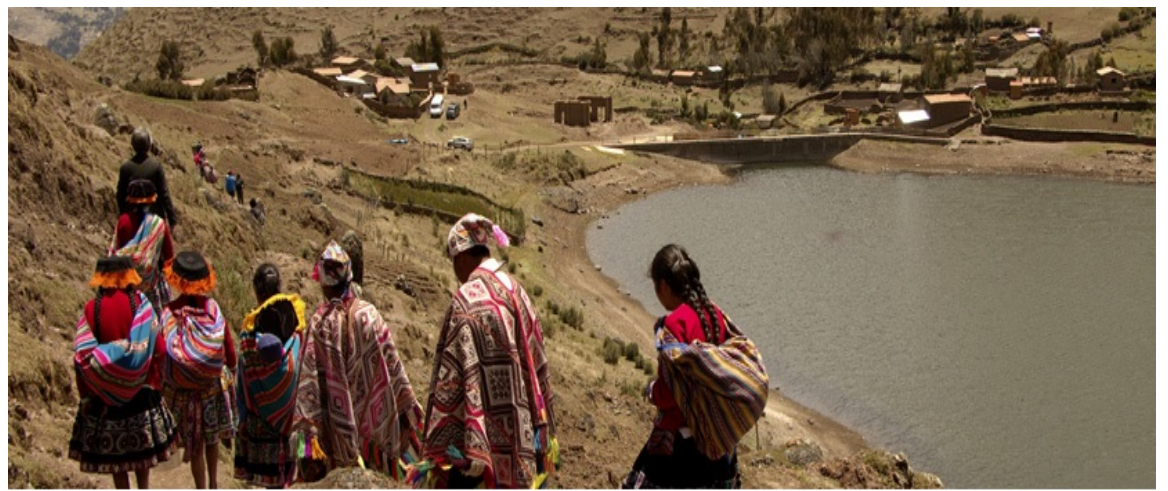

Figure 1. Walk in potato parc in Pisaq, Cusco (Peru), @ Manon Koningstein (CIAT). 
places where such problem seemed to be a distant reality. Water is a dynamic and bulky fluid, with tendency to transform and to "migrate" from place to place [16], and that very characteristic is responsible for both droughts and floods. Such dynamics are becoming increasingly accentuated due to climate change [17].

The Moroccan NGO Dar Si Hmad attested, through one of its fog harvesting experiments in the Atlas Mountains in Morocco, that a water surplus can have a positive social impact other than the rather obvious economic one. Previously, in the villages that benefitted from the new water source, women had the burden to walk long distances to get water for their households. Young girls had similar roles, and most of them did not have time to go to school, with the consequent generation of gender unbalance. The extra water supply to the village alleviated pressure not only in the existing groundwater sources but also on the female gender, allowing for a different social mechanic to emerge and for new opportunities to arise.

World scenarios of water scarcity are mostly related to many variables other than only meteorological/climate factors. Conflicts and civil war, especially in Sub-Saharan Africa and the Middle East, are relevant for the lack of water infrastructure in some countries that belongs to these macro regions. Poor governance almost always has a direct link to scarce water services and quality, and this enhances the link between good public policies and an adequate water supply. However, even if the local government is minimally responsible and water resources are abundant, water stress will be experienced if the region is heavily populated. This is the case of some regions of Asia, notably the Indian Subcontinent and China's east provinces, which are not, from a geographical point of view, water-scarce regions. However, the weight of human presence in these regions is sufficiently high to put them in a sensible situation.

Other world regions, such as South and North America, differs in water usage and available fresh water resources, although both subcontinents show a wide variety of climates and landscapes, as well as an uneven distribution of surface and groundwater. The United States is the heaviest water user in the world, averaging 455 - 530 litres/day per person [1]. On the contrary, South American countries use disproportionally less water per capita. For instance, Europe's heaviest water consumer is Italy with 241 litres/day per person, far behind the United States. However, Europe's large population and migration crisis are putting an extra burden in its water resources, even in rain-abundant countries like the United Kingdom, and especially in large metropolitan areas.

\section{Fog Phenomena}

Fog collection efficiency rate proved to be dependent on both the wind speed and the fog droplet size. Therefore, understanding fog phenomena and formation process is essential for application and technical improvement [18]. Fog can be defined as a cloud of water vapour condensed into small water droplets, with 
1 to 40 microns diameters, suspended in the atmosphere at ground level. Their small size prevents them from settling rapidly. Fog has fall velocities from less than $1 \mathrm{~cm} / \mathrm{s}$ to approximately $5 \mathrm{~cm} / \mathrm{s}$. These rates of fall are sufficiently low to modify the angle at which the drops fall, depending on wind speed. For this reason, even the mildest wind will transport them horizontally [19].

Fog characteristics differ in relation to its formation process. The most frequent fog typologies are radiation fog, advection fog and orographic fog. Radiation fog is common in autumn and winter in temperate latitudes; it is associated with the radiative cooling of the lowest layers of the atmosphere during clear and cool nights (Figure 2(a)). Advection fog is always associated with horizontal movements of air currents and can result in two different manners. The cooling of surface air can occur when warm, humid air moves across a cold surface. If the air is cooled to the dew point, fog is produced. Advection fog can also be termed high-elevation fog when it is produced by the wind blowing clouds over mountains or hills. This fog will persist as long as the cloud is forced over the terrain (Figure 2(c)). Orographic fog is formed when warm, damp air moves toward mountains; as it rises along the slope, it expands and is cooled (Figure 2(b)). If it is sufficiently humid, then fog will form on the surface [20]. However, discerning these processes can be difficult, as they may occur simultaneously.

\section{Fog Water Harvesting: State of the Art and Common Mechanism}

Present-day technologies for harvesting water from the fog are passive, cheap to install and easy to maintain. Such maintenance is made largely by the community, which benefits from the technology, which is a quintessential requirement for the harvesting devices' proper functioning and crucial for the survival of a project of such nature [20]. Although the numbers of solutions already found by researchers and designers is significant, they mostly consist of some fundamental parts, such as the mesh, the supporting structure and the distribution network/storage facilities. The functioning is based on the same mechanism: wind-driven fog water droplets are caught in the meshes, then they group together and slowly move down through gravity to reach reservoirs.

Among the many variants that can condition the efficiency of this technology, one of the most relevant is the fog's LWC (Liquid Water Content), allied with a sufficient wind speed to transport enough water to the meshes [19] [21] [22]. In Schemenauer and Cereceda's experiments in Chile, an assessment of the total

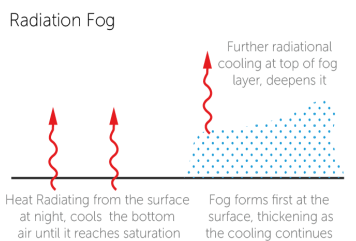

(a)

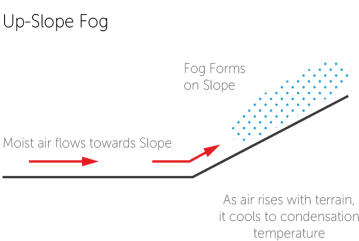

(b)

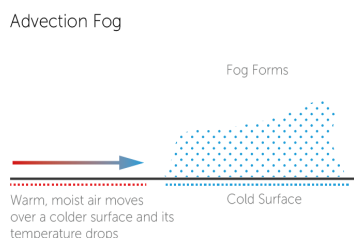

(c)

Figure 2. (a), (b), (c) Types of fog. Diagram @ Federico Lorenzon. 
water collection rate using one hundred Large Fog Collectors (LFC) showed the potential to harvest an average 15.000 liters of water a day, more than enough for a whole village. In intense fog conditions, the nets collected more than 100.000 liters/day of water [8] [20] [23].

The most widespread fog collector used is the LFC, which is a two-dimensional textile surface sustained by a rigid structure anchored to the soil, with a pipe connection to a reservoir in most cases. Some other morphologies exist, such as the three-dimensional collectors, which draw their main advantage to the larger surface area adaptable to different wind directions. Another example is the Warka Tower project, in Ethiopia. Water collected from fog falls within World Health Organization (WHO) fresh water standards, a large advantage of such technology, which can provide easy and fresh water to people who dwell in regions where access to such goods would require the installation of major infrastructures. Water infrastructures may not be affordable for some country's annual budget or deemed to be secondary investments, while fog harvesting technology, although far from reaching its full potential, is undoubtedly a promising alternative that will show increasing positive outcomes.

\section{Application of Fog Harvesting Technology}

The most productive conditions for fog water harvesting are found on mountains where the wind moves clouds over the surface of the ground. In contrast, radiation fogs in valleys, or sea fogs on the coast, are considered less productive. This is because of the lower wind speeds and lower fog liquid water contents normally encountered in these situations but can also be attributed to the low-tech and low-cost technology. Current employments of fog nets include applications in two major sectors:1) Fresh water supply, meeting WHO drinking water standards, to rural communities and groups of homes; 2) Water for reforestation and for habitat maintenance, where it is impractical to import water from conventional sources [20].

However, with technological improvement of the textile mesh, the study and monitoring of fog pattern and involvement of locals, the technology seems promisingly applicable in other fields. In the following section, general relationships between the fields of application and social and economic aspects are established. In this way, it is possible to analyze new opportunity for fog harvesting application and to express some considerations on feasibility. The application investigated are agriculture, domestic use, urban design, building component and outdoor activities, while fabrication processes, market and sustainability of the product are some of the parameters included in the evaluation.

\subsection{Opportunity for Implementation: Agriculture}

Starting with agriculture, one option is that already existing methods, for example the ones which involve the use of meshes to protect vegetation, is converted into fog harvesting meshes and the textile material improved and connected to 
the irrigation system. Cost of materials' performance testing in order to find an optimal mesh-material combination and production would be high. The novel device can be standardized and made for mass production due to a desirably simple, feasible shape. However, constant exposure to weather hazards means increased maintenance difficulty.

\subsection{Opportunity for Implementation: Private Domestic Use}

On the domestic use, possibilities of fog harvesting are open, such as devices to collect fog water for cooking, toilet or irrigation use. The existing technology would need to be incremented and scaled to the private users' needs. Possibility for mass production exists, which demands a standardized design to make the device user-friendly and its production easy. The general European and North-American public, though, does not perceive water scarcity as a serious problem, leading to a low market attractiveness of this product in wealthy countries, while it would not be affordable in poor countries. Improvement in home's sustainability, at the same time, is not incisive because of results that are more evident are coming from other systems, such as rainwater recycle and management.

\subsection{Opportunity for Implementation: Building Components}

When it comes to building components, there are several options to consider, such as generating a "smart facades" that textile meshes in the facade design, so it could be combined with green facades and at the same time provide water for it. Another option does not include just facades, but different building components such as terrace fences, canopies, or decorative elements that would be made of meshes integrated along with the structure. Their main purpose would be to provide water and to be connected to the water supply system in the building in order for water to be used for washing or planting. Cost-wise, as well as production and implementation in the building, it is rather a considerable investment. Moreover, since buildings differ from each other, the standardization and mass production is not as easy as for the other scenarios. Regarding durability and life cycle, they might have a high technical maintenance need and not so virtuous life cycle. However, in term of market attractiveness, this innovation in building technologies can be considered a good opportunity for the European market, also due to the fact that this one specifically improves the sustainability of the building itself.

\subsection{Opportunity for Implementation: Outdoor Activities}

Outdoor activities, such as mountain climbing, hiking or camping in nature are becoming more popular because cities are transforming into extremely polluted environments. Thinking in terms of fog harvesting and how to integrate it with these activities, one option could include a fog collecting tent that could be a solution for providing water for showering, washing etc. Integrating the fog collec- 
tion devices into outdoor activities does not require expensive materials and technology, as well as production. The device can be easily standardized and designed for mass production, since it is desirable to be user friendly. Moreover, durability and maintenance needs are not difficult to achieve, since it is not all the time exposed to the hazards. When it comes to the market attractiveness, it is a new and enticing concept that, along with appealing design can, attract investments from different stakeholders of the sport sector. Although all these points are highly desirable, this device does not make a significant improvement in sustainability, since it is being used individually and from a reduced segment of people.

\subsection{Opportunity for Implementation: Urban Design}

The urban design sector is undoubtedly one of the most open to the positive innovations, which can be developed in urban environments through the fog harvesting technique. Even if the cost of experimentation on material and technology production could be high, European funds could be used to promote project to raise the awareness of water scarcity problems. Studies of urban metabolism and loop closing are more and more diffused and thus urban design is not to be considered only as an extra part of the city, but also an important part of the space perception. It often represents a landmark and meeting point and it can affect people's experience of space and personal behavior. Regarding the fact that each urban project is different, some possibilities for standardization and modularity are still open, depending on the type of the project itself. A wide range of private and public stakeholder could be attracted and involved (such as municipality, NGO, EU funds). Therefore maintenance and durability should not represent a problem. Since this is not a single-user product but it opens several different multi-users options, it can improve the sustainability of the surrounding.

As a result of the previous considerations, urban design emerges as a promising field for fog harvesting implementation. The major influencing factor is the opportunity to a wider public and to have a relevant positive impact on environment. Due to population growth, cities are experiencing a more and more critical land, water and energy consumption crisis instead of showing efficient use of resources. In this perspective, urban fog harvesting would also improve people's attitude towards water management practice.

\section{Regional Application Scenarios}

Taking into consideration some foggy but urbanized regions both in poor contexts and in rich ones (Tenerife, Lima and Milan), WaLi team proposed some possible urban scale application of fog-harvesting devices [24]. Tenerife is an island famous for its spring-like weather year-round and many resorts that make it a top attraction in world tourism. The region experiences massive tourism during summer season, which places an extra burden on the island's little groundwater resources. Apart for its groundwater, the island experiences heavy 
fog that is present on the mountains but especially near the coast, a huge opportunity for a fog harvesting project. With the scope of increasing the installation's success, in each city/region of intervention, a selection of optimal places both for fog collection and for accessibility for local was made. That includes Tenerife Island's Plaza de Europa in Puerto de la Cruz, parque Doña Chana in La Orotava, Plaza Doctor Pérez Caceres in Vilaflor and an empty, triangular terrain in Granadilla.

Lima is the capital of Peru and one of the driest metropolis in the world. It experiences heavy fog, particularly during the morning. The city's deficiency in water distribution infrastructure and its many needy peripheral inhabitants make this intervention location an optimal place for a fog harvesting experiment. In Lima, all project intervention places were squares, with variable proximity to the city centre; the intervention would start in Plaza San Martín and the Maria Reiche Miraflores Park, very central in Lima's urban fabric, then progressively expanding towards the periphery, passing by the Plaza de Armas until Mercado Primero de Mayo, in the hilly outskirts of the city.

Lastly, the fog-shrouded city of Milan, which is Italy's main economic hub but also one of Europe's foggiest city. Intervention here would start in Piazza Leonardo da Vinci in the Politecnico di Milano campus, open to students, professors and enthusiasts alike. Additional installations would be placed near to Bibliotecadegli Alberi park and Piazza Gae Aulenti, to represent, together with Bosco Verticale, a sustainability landmark and then to Bovisa district, famous in the past for its pollution but now in a continuous urban rehabilitation process. These are only few examples but clearly show how much, with studies of local climatic patterns and population needs, fog harvesting technology can have a positive impact on society and help facing water variability due to climate changes.

\section{Conclusions}

This article dealt with fog water harvesting, starting from current world water-stress situation and its consequences on economy, health and social relations. Through a description of principal fog phenomena, fog collection process, traditional fog-harvesting devices and projects state of the art, it emerged that some field of application are still unexploited. Reporting a study conducted by WaLi team, considerations on building components, urban design or outdoor activities among the others were made, with specific reference to some foggy selected areas (Tenerife, Lima and Milan). Therefore, the application of fog harvesting in cities is expressed as a promising opportunity, which can be a chance for urban regeneration, sustainable improvement and construction of water management awareness and virtuous practices.

\section{Acknowledgements}

WaLi research was supported by Alta Scuola Politecnica, a graduate fellowshipamong Politecnico di Milano and Politecnico di Torino. The authors thank the 
rest of WaLi team (Runze Li, Federico Lorenzon, Sara Miladinovic), and academic tutors Carol Monticelli ( $\mathrm{PhD}$ in Technology of Architecture for the Built Environment) and Gabriela Fernandez (PhD, Department of Architecture and Urban Studies).

\section{References}

[1] WWAP (United Nations World Water Assessment Programme) (2006) The United Nations World Water Development Report 2: Water, a Shared Responsibility. Paris, UNESCO and Berghahn Books, New York.

[2] Domen, J.K., Stringfellow, W.T., Camarillo, M.K. and Gulati, S. (2014) Fog Water as an Alternative and Sustainable Water Resource. Atmospheric Research, 16, 235-249. https://doi.org/10.1007/s10098-013-0645-Z

[3] Cereceda, P., Larrain, H., Osses, P., Farías, M. and Egaña, I. (2008) The Climate of the Coast and Fog Zone in the Tarapacá Region, Atacama Desert. Chile. Atmos. Res., 87, 301-311. https://doi.org/10.1016/j.atmosres.2007.11.011

[4] Cereceda, P., Larrain, H., Osses, P., Farías, M. and Egaña, I. (2008) The Spatial and Temporal Variability of Fog and Its Relation to Fog Oasis in the Atacama Desert. Chile. Atmos. Res., 87, 312-323. https://doi.org/10.1016/j.atmosres.2007.11.012

[5] Ritter, A., Regalado, C.M. and Aschan, G. (2008) Fog Water Collection in a Subtropical Elfin Laurel Forest of the Garajonay National Park (Canary Islands): A Combined Approach Using Artificial Fog Catchers and a Physically Based Impaction Model. J.of Appl. Met., 9, 920. https://doi.org/10.1175/2008JHM992.1

[6] Marzol, M.V. and Megia, J.L.S. (2008) Fog Water Harvesting in Ifni, Morocco. An Assessment of Potential and Demand. Die Erde, 139, 97-119.

[7] Olivier, J. (2002) Fog-Water Harvesting along the West Coast of South Africa: A Feasibility Study. Water SA, 28, 349-360. https://doi.org/10.4314/wsa.v28i4.4908

[8] Schemenauer, R.S., Cereceda, P. and Fuenzalida (1988) A Neglected Water Resource: The Chamanchaca of Northern Chile. Bulletin American Meteorological Society, 69.

[9] Abdul-Wahab, S.A., Al-Damkhi, A.M., Al-Hinai, H., Al-Najar, K.A. and Al-Kalbani, M.S. (2010) Total Fog and Rainwater Collection in the Dhofar Region of the Sultanate of Oman during the Monsoon Season. Water Int., 35, 100-109. https://doi.org/10.1080/02508060903502984

[10] Al-Hassan, G.A. (2009) Fog Water Collection Evaluation in Asir Region-Saudi Arabia. Water Resource Management, 23, 2805-2813. https://doi.org/10.1007/s11269-009-9410-9

[11] Estrela, M.J., Valiente, J.A., Corell, D. and Millán, M.M. (2008) Fog Collection in the Western Mediterranean Basin (Valencia Region, Spain). Atmos. Res., 87, 324-337. https://doi.org/10.1016/j.atmosres.2007.11.013

[12] Shanyengana, E.S., Sanderson, R.D., Seely, M.K. and Schemenauer, R.S. (2003) Testing Greenhouse Shade Nets in Collection of Fog for Water Supply. J. Water Supply Res. Technol. AQUA, 52, 237-241 (London, UK).

[13] WWAP (United Nations World Water Assessment Programme) (2015) The United Nations World Water Development Report. Water for a Sustainable World. Paris.

[14] JMPWSS (Joint Monitoring Programme for Water Supply and Sanitation) (2015) 2015 Update and MDG Assessment: Progress on Sanitation and Drinking Water. Geneva, UNICEF and World Health Organization 2015. 
[15] WWAP (United Nations World Water Assessment Programme) (2015) The United Nations World Water Development Report 2015: Water for a Sustainable World. Paris, UNESCO.

[16] Hanemann, W.M. (2005) The Economical Conception of Water. Giannini Foundation of Agricultural Economics, July, 61-88.

[17] European Environmental Agency (2009) Europe's Onshore and Offshore Wind Energy Potential. EEA Technical Report.

[18] Rivera, J. (2011) Aerodynamic Collection Efficiency of Fog Water Collectors. Atmos. Res., 102, 335-342. https://doi.org/10.1016/j.atmosres.2011.08.005

[19] Schemenauer, R.S. and Cereceda, P. (1994) A Proposed Standard Fog Collector for Use in High-Elevation Regions. J. Appl. Meteorol., 33, 1313-1322. https://doi.org/10.1175/1520-0450(1994)033<1313:APSFCF >2.0.CO;2

[20] Schemenauer, R.S., Cereceda, P. and Osses, P. (2015) Fog Water Collection Manual, Revised Ed.

[21] Schemenauer, R.S. and Joe, P.I. (1989) The Collection Efficiency of a Massive Fog Collector. Atmos. Res., 24, 53-69. https://doi.org/10.1016/0169-8095(89)90036-7

[22] Bridgman, H.A., Walmsley, J.L. and Schemenauer, R.S. (1994) Modelling the Spatial Variations of Wind Speed and Direction on Roundtop Mountain, Quebec. Atmos.-Ocean, 32, 605-619.

[23] Klemm, O., Schemenauer, R.S., Lummerich, A., Cereceda, M.V., Corell, D., van Heerden, J., Reinhard, D., Gherezghiher, T., Olivier, J., Osses, P., Sarsour, J., Frost, E., Estrela, M.J., Valiente, J.A. and Fessehaye, G.M. (2012) Fog as a Fresh Water Resource: Overview and Perspectives. AMBIO 2012, 41, 221. https://doi.org/10.1007/s13280-012-0247-8

[24] Morichi, G., Calixto, L., Lorenzon, F., Li, R. and Miladinovic, S. (Unpublished) WaLi: Water For Life Exploring Urban Landscapes for Water Harvesting with New Technologies. Alta Scuola Politecnica Report, Milano Torino 2017, 43-54; 73-83. 